\title{
Investigation on application of a typical mortar for clinker in prefabricated façade panels - test's results
}

\author{
Marta Kałuża*, Jacek Hulimka, Jan Kubica, and Kamil Kozdroń \\ Silesian University of Technology, Faculty of Civil Engineering, Department of Structural \\ Engineering, Akademicka 5, 44-100 Gliwice
}

\begin{abstract}
In the last period, openwork facades have become very fashionable and commonly used in modern public buildings. They are characterised by an outstanding design and proper lighting of the interior spaces, while providing lightweight solution of the façade. The typical erecting method of an openwork façade - often made of ceramic components - is in-situ bricklaying using specific mortar dedicated to clinker elements. Unfortunately, ensuring proper executive conditions and preparation of the ceramic elements is not always possible. Hence, together with the development of architectural requirements, there has appeared a natural need to create prefabricated elements, which reflect the real bricklaying wall and ensure the safety of the solution. The paper presents a laboratory study on untypical application of a mortar for clinker, used to prefabrication of an elevation panel. The tests of mortar and solution of openwork prefabricated panel made using this mortar and special-shaped clinker components are presented and discussed. The material tests include determination of the strength properties of three types of mortar mixture, differing of each other by water content. The second part of this paper presents the laboratory tests of prefabricated panels, made using previously tested mortars, supported and loaded similar to the real working conditions.
\end{abstract}

\section{Introduction}

Openwork facades have recently started playing a significant role in modern masonry construction, mostly due to their architectural values and structural aspect as well: lightweight solution of the facade. They are usually erected in-situ, using specified masonry units and dedicated types of mortar. Based on the example of a freshly designed building in Katowice (Upper Silesian District, Poland), new and much more complex architectural visions have led to the natural need for replacing, at least partially, the standard way of structures execution with prefabrication method. This, in turn, entails the necessity for specific laboratory tests to determine the real possibilities of mortar application into prefabricated elements. All the tests are supposed to indicate a modified mortar type, appropriate for prefabrication purposes, here: for openwork prefabricated panels.

*Corresponding author: marta.kaluza@polsl.p1 
specified type of masonry units, has a significant influence on the behaviour of a structural element or an entire structure. It is essential to provide a mortar characterised by appropriate mechanical parameters, both of the mortar itself (compressive and bending strength) and in the context of mutual cooperation with masonry units (bond strength).

Untypical requirements, associated with an attempt of application of mortar into the reinforced prefabricated panel, may also need the mortar to achieve a higher level of workability. This feature mostly depends on the mortar's water content, but may also be associated with water retention and internal friction - because of aggregate properties, hydraulic strength of binder or mix proportions [1].

Despite a general conviction that increase in water-binder ratio leads to deterioration in mechanical parameters of mortar, different strength values obtained in many research studies do not seem to confirm this rule in each case. The reasons are associated with many additional factors, for which the increase in water content may finally result in the growth of analysed strength. According to research study concerning investigation on flexural bond strength [1] (and remaining previously indicated mechanical parameters [2]) of natural hydraulic lime mortars and clay bricks, the higher water content in tested mortar mixes was implemented, the bigger values of flexural bond strength were achieved. Summarising, an attempt to find an overall and unequivocal relationship between the water content and the selected mechanical parameter, especially the bond strength, seems to be relatively difficult and each configuration should be analysed independently. Hence, the content of mixing water was tested and was the only modified parameter in the presented studies.

\section{Description of research issue}

A new type of an external enclosure wall was designed as a typical three-layer construction consisted of main internal load-bearing wall (made of monolithic concrete), layer of thermal insulation covered by thin clinker tiles and external finishing layer. This finishing of the façade was created as independent front elevation in form of reinforced masonry openwork wall with fully orthogonal pattern of special clinker masonry units.

The basic project (created by the architects) considered an execution of the external openwork wall by bricklaying at the building site. However, such a solution could generate many difficulties during workmanship because the distance of this wall to the main part of the load-bearing wall was only $12 \mathrm{~cm}$ and it was too short distance for the proper making of the brickworks, especially for correctly filling by mortar all the joints. To prevent the executive problems a prefabrication of the finishing layer of elevation was proposed and tested in the laboratory of Faculty of Structural Engineering at Silesian University of Technology.

After all conducted tests, described in this paper, the authors proposed some modifications both in the type of mortar and construction of the prefabricated panels (introduction of a steel external frame connected with internal reinforcement to create a spatial truss) to prevent unexpected and quite dangerous failure of the panels. This solution was more detailed presented in [3], where laboratory tests of modified prefabricated panels made using different type of mortar with 4 and 5 litres of mixing water were described.

The prefabricated panels, presented in this paper, were constructed as reinforced masonry elements consisted of clinker opened masonry units integrated by the mortar joints (vertical and horizontal), where the reinforcement was placed. To prefabricate of these elements a cement nano-mortar for bricklaying of clinker units were used. Appropriate execution of the panels was connected with an adequate workability of a flow mixture, which is tied up with mixing water used in the mortar. The application of recommended by manufacture amount of water $(3 \div 3.5$ litres per one $25 \mathrm{~kg}$ bag of dry mortar mix) did not allow elements to be 
made. The correct filling of the gap between the units was impossible, because of too compact consistency of the mortar. So, it was required to change the mixing ratio and increase the amount of water to guarantee the higher workability of the mortar.

Three different content of mixing water: 4.0, 4.5 and 5.0 litres (per one bag) were taken to prepare a mortar used to prefabrication of the panels, intended for laboratory tests. This untypical application of the mortar, serving as a filling material in masonry panels, requires also performing primary material tests. These tests allow checking the influence of specific amount of water (significantly different from the manufacture's recommendations) on the mechanical parameters of the mortar.

\section{Characteristics of laboratory tests}

\subsection{Material testing}

To determine the strength properties of hardened mortar a ready mix mortar was taken and modified with various amount of mixing water. Three contents of mixing water: 4.0, 4.5 and 5.0 litres per one bad of dry mix $(25 \mathrm{~kg})$ were analysed. The tests of mechanical parameters flexural and compressive strength - were tested according to EN 1015-11:1999 [4] regulations. The properties were determined on small cuboids specimens with the dimension of $160 \times 40 \times 40 \mathrm{~mm}$. The specimens were tested on day 7, 14, 21 and 28 after preparation. Three specimens for every selected day of testing were prepared. Based on the maximum load, applied to the sample, the flexural strength $\left(\mathrm{f}_{\mathrm{f}}\right)$ was calculated. Compressive strength $\left(f_{c}\right)$ was determined on broken sample halves, taking to calculation maximum compressive force. Fig. 1 and 2 present the samples prepare to: a) three-points bending tests, and b) compression tests.

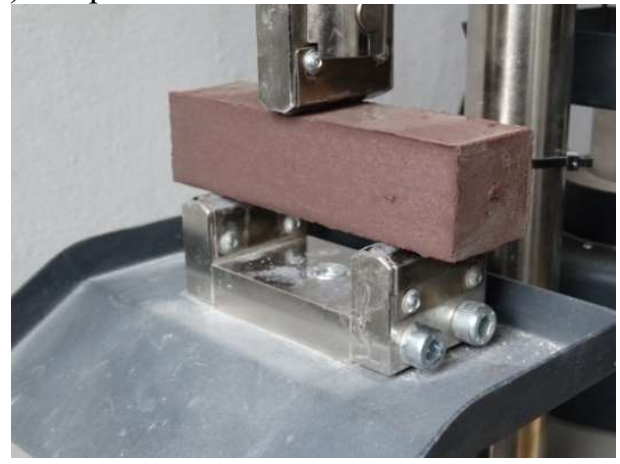

Fig. 1. Sample prepared to flexural test.

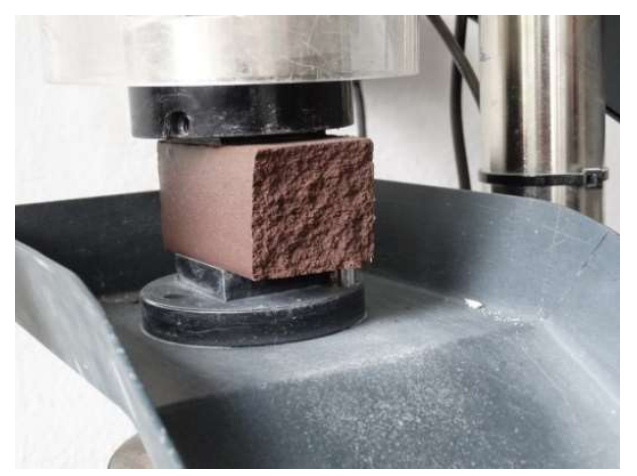

Fig. 2. Sample prepared to compressive test.

\subsection{Testing of façade panels}

\subsubsection{Prefabricated panels - description}

The prefabricated façade panels were consisted of clinker opened masonry units with the dimension of $240 \times 170 \times 115 \mathrm{~mm}$, integrated by the mortar joints of $30 \mathrm{~mm}$ width. The arrangement of the masonry units in one panel was $4 \times 4$. In every vertical and horizontal joint carbon steel bars, with diameter of $6 \mathrm{~mm}$, formed as loops were placed. The element was provided with four screws M10 - welded to the reinforcement - serving to set up the panel to a steel frame structure (supports). After prefabrication of the element, the screws led out 
from the panel. Fig. 3 presents the view of arrangement of the units in one panel and the skeleton of the reinforcement with fixed mounting screws.

a)

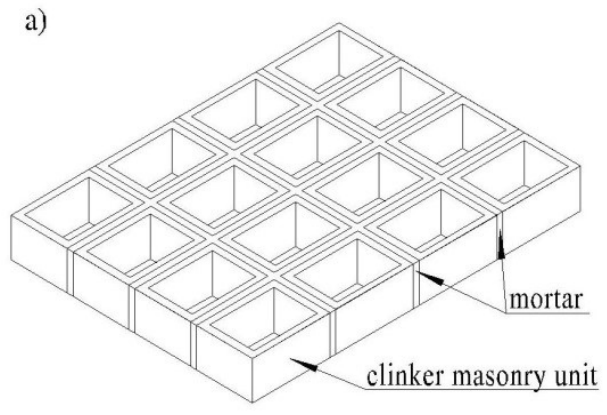

b)

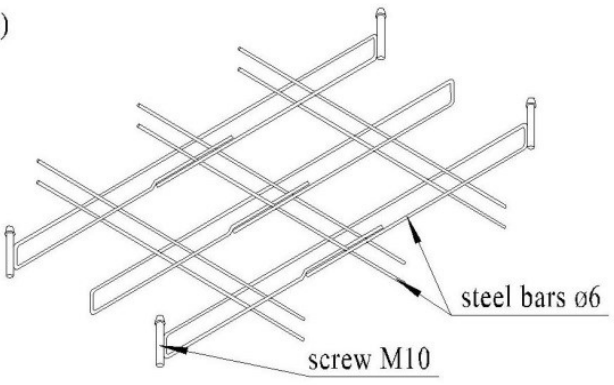

Fig. 3. The prefabricated panel (identical to that described in [3]): a) general view, b) reinforcement

Series covering testing of the entire panels includes four elements. All these elements were made with the same type of mortar, but with different amount of mixing water applied during preparation of the mortar and prefabrication of the panels. The specimens were signed as: $H L-r s-4 \times 4-n-i$, where following symbols means: $H L$ - mode of loading (horizontal loading), $r s$ - ribbed reinforcement steel, $4 \times 4$ - arrangement of the ceramic masonry units filling, $n$-content of mixing water used during prefabrication (in litres per one bag of mortar mix), $i$ - number of tested specimen. Three level of water content were taken into account: 4.0 litres (one panel), 4.5 litres (two panels) and 5.0 litres (one panel).

\subsubsection{Test stand and measuring equipment}

The prefabricated panels were tested in a special test stand designed, reflected the real situation - position of the panels on the elevation of the building and typical out-of-plane loading. Each element was fixed to the steel frame (made of transverse profiles) using screws led out from the panel and steel plates mounted direct to the steel supporting profiles. The test stand together with an element prepared to the test is shown in Fig. 4.

The elements were loaded in one cycle, up to the reaching the state of failure. The load was acting in direction perpendicular to the element's surface and was located on the crossing of joints in form of four concentrated force. The load was transferred to the element using steel traverse and hydraulic jack (Fig. 5).

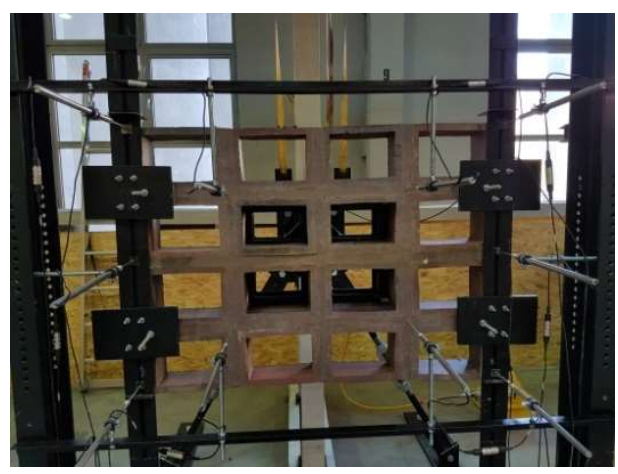

Fig. 4. Element prepared to test and instrumented with inductive gauges.

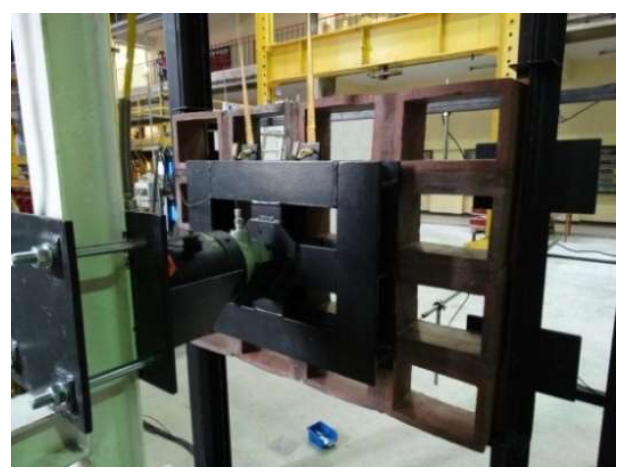

Fig. 5. Loading equipment - steel traverse and hydraulic jack. 
During the tests, applied load and displacement perpendicular to the specimen surface were recorded. The displacement was determined in ten points and was measured with the LVDT gauges and frequency of $2 \mathrm{~Hz}$. Six points were placed on the vertical steel supporting profiles (three at every side) and four were located in the same place, where the load was applied. The measuring equipment is visibly on Fig. 4.

\section{Test results}

\subsection{Mortar strength parameters}

In the Table 1 the maximum load $\left(\mathrm{P}_{\mathrm{f}}\right)$ applied to each sample and flexural strength calculated $\left(f_{x}\right)$ for all specimens are listed. The table includes all three types of specimens, differing in water content (4.0 litres, 4.5 litres and 5.0 litres). The specimens were signed as: FS - flexural strength, 00 - number of days after preparation. In Table 2 only mean values of compressive strength, determined on the samples obtained after bending tests, are summarized. The samples are designed in the same way as in case of flexural strength, considering only that CS means compressive strength.

Table 1. Failure loads and flexural strength of tested samples.

\begin{tabular}{|c|c|c|c|c|c|c|c|c|c|}
\hline \multirow{3}{*}{ Samples } & \multicolumn{3}{|c|}{4.0 litres of water } & \multicolumn{3}{|c|}{4.5 litres of water } & \multicolumn{3}{|c|}{5.0 litres of water } \\
\hline & $P_{f}$ & $f_{f}$ & $f_{f, \text { mean }}$ & $P_{f}$ & $f_{f}$ & $f_{f, \text { mean }}$ & $P_{f}$ & $f_{f}$ & $f_{f, \text { mean }}$ \\
\hline & {$[\mathrm{kN}]$} & \multicolumn{2}{|c|}{$\left[\mathrm{N} / \mathrm{mm}^{2}\right]$} & {$[\mathrm{kN]}$} & \multicolumn{2}{|c|}{$\left[\mathrm{N} / \mathrm{mm}^{2}\right]$} & {$[k N]$} & \multicolumn{2}{|c|}{$\left[\mathrm{N} / \mathrm{mm}^{2}\right]$} \\
\hline \multirow{3}{*}{ FS-07 } & 0.61 & 1.42 & \multirow{3}{*}{1.55} & 0.56 & 1.31 & \multirow{3}{*}{1.32} & 0.40 & 0.95 & \multirow{3}{*}{0.92} \\
\hline & 0.69 & 1.63 & & 0.58 & 1.36 & & 0.39 & 0.92 & \\
\hline & 0.69 & 1.61 & & 0.55 & 1.29 & & 0.38 & 0.90 & \\
\hline \multirow{3}{*}{ FS-14 } & 0.89 & 2.09 & \multirow{3}{*}{1.90} & 0.72 & 1.69 & \multirow{3}{*}{1.63} & 0.48 & 1.12 & \multirow{3}{*}{1.14} \\
\hline & 0.72 & 1.69 & & 0.69 & 1.62 & & 0.50 & 1.17 & \\
\hline & 0.82 & 1.92 & & 0.68 & 1.59 & & 0.49 & 1.14 & \\
\hline \multirow{3}{*}{ FS-21 } & 1.10 & 2.57 & \multirow{3}{*}{2.48} & 0.83 & 1.95 & \multirow{3}{*}{2.00} & 0.52 & 1.23 & \multirow{3}{*}{1.23} \\
\hline & 1.04 & 2.43 & & 0.87 & 2.04 & & 0.52 & 1.21 & \\
\hline & 1.04 & 2.45 & & 0.86 & 2.02 & & 0.54 & 1.26 & \\
\hline \multirow{3}{*}{ FS-28 } & 1.06 & 2.49 & \multirow{3}{*}{2.56} & 0.87 & 2.04 & \multirow{3}{*}{2.06} & 0.54 & 1.27 & \multirow{3}{*}{1.28} \\
\hline & 1.07 & 2.50 & & 0.89 & 2.09 & & 0.56 & 1.30 & \\
\hline & 1.14 & 2.68 & & 0.88 & 2.06 & & 0.55 & 1.28 & \\
\hline
\end{tabular}

Table 2. Compressive strength of tested samples.

\begin{tabular}{|c|c|c|c|}
\hline \multirow{2}{*}{ Samples } & \multicolumn{3}{|c|}{$\begin{array}{c}\text { Mean compressive strength } \\
f_{\text {c,mean }}\left[\mathrm{N} / \mathrm{mm}^{2}\right]\end{array}$} \\
\cline { 2 - 4 } & 4.0 litres & 4.5 litres & 5.0 litres \\
\hline CS-07 & 5.34 & 4.15 & 2.99 \\
\hline CS-14 & 5.94 & 5.09 & 3.84 \\
\hline CS-21 & 6.04 & 5.33 & 4.44 \\
\hline CS-28 & 6.34 & 5.50 & 4.47 \\
\hline
\end{tabular}

The material test conducted indicated a significant influence of the amount of water, used to preparation of the mortar mix, on the mechanical properties of a hardened mortar. This situation is more visible in the case of flexural strength, where changing of water content from 4.0 litres to 5.0 litres resulted in exact double reduction $(100 \%)$ of the strength. In the 
case of a compressive strength, the parameter reduction was not so significant (compared with flexural strength). The increase of the amount of water by 0.5 litre caused only $13 \%$ decrease in compressive strength, while the increase by one litre resulted in a $30 \%$ decrease in this parameter.

The increase in strength of mortar (flexural and compressive) in the next days of curing is shown in the diagrams in Fig. 6 and 7. The lines are assigned to specific amount of water used during mixing the mortar.

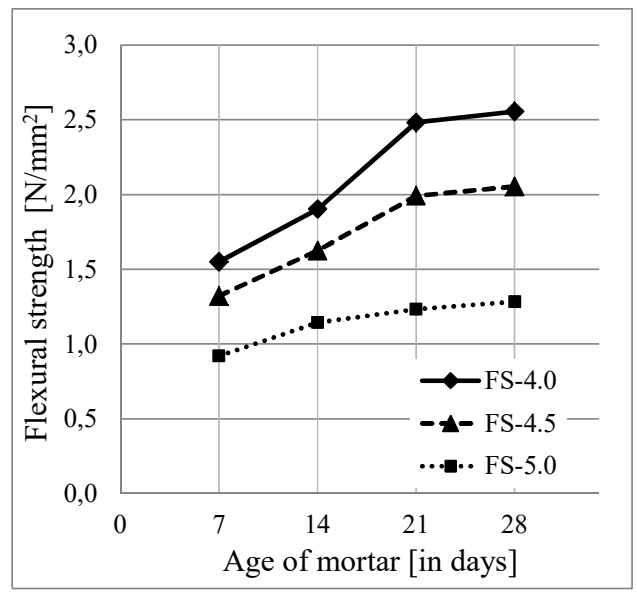

Fig. 6. The increase in flexural strength (mean values) during curing process.

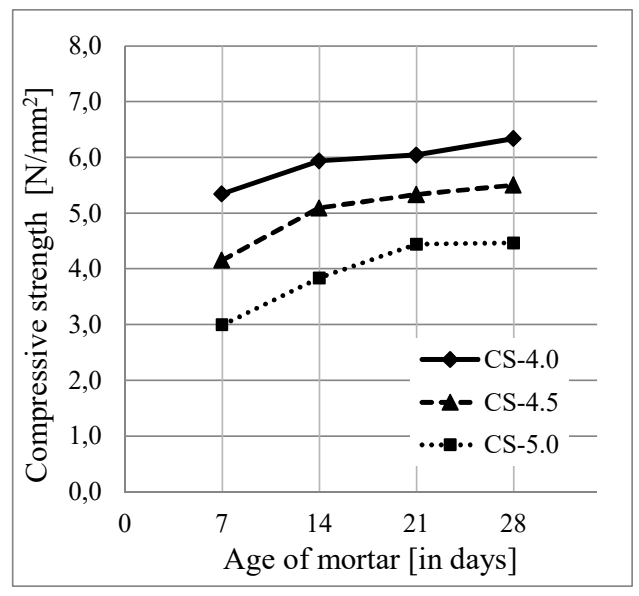

Fig. 7. The increase in compressive strength (mean values) during curing process.

In the specimen with 4.0 litres of water (what was slightly more than in producer' recommendation: $3.0 \div 3.5$ ) an increase in flexural strength, during curing of the mortar, was significant - almost doubling. However, in sample with 5.0 litres of water an increase in flexural strength was rather small, less than $40 \%$. In the case of increasing in compressive strength, an opposite situation was observed. The application of 4.0 litres mixing water caused only $18 \%$ increase in strength - during curing process, while 5.0 litres caused almost $50 \%$ increase in properties.

An important observation, visible in almost all samples, was a stabilization of the strength parameters already in $21^{\text {st }}$ day after preparation of the mortar. This made it possible to previous usage of the elements, without worrying about premature cracking or failure.

\subsection{Behaviour of prefabricated panels}

\subsubsection{Cracking stage}

The cracking moments $\left(\mathrm{M}_{\mathrm{cr}}\right)$ of all panels, calculated on the basis of recorded cracking loads $\left(\mathrm{P}_{\mathrm{cr}}\right)$, were specified and listed in Tab. 3.

During the tests, a displacement of specific points was measured. The relevant measuring points were placed on the panel' surface (4 points on the joints' crossing) and vertical supporting profiles (4 points). Based on the values measured, the deflection of a prefabricated element was calculated. The scheme of the deflection calculations is shown in Fig. 8. The deflection noticed at cracking stage is also given in Tab. 3 . 


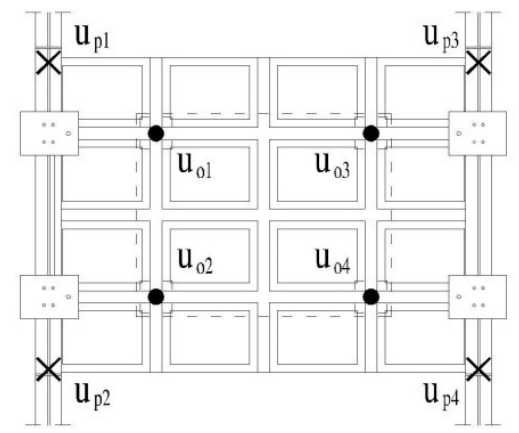

$\mathrm{u}_{\mathrm{pi}}$ - measuring point of the deflection on the support

$\mathrm{u}_{\mathrm{oi}}$ - measuring point of the displacement on the prefabricated element

Deflection of the entire prefabricated element

$$
\mathrm{u}=\frac{\sum_{i=1}^{4} \mathrm{u}_{\mathrm{oi}}}{4}-\frac{\sum_{\mathrm{i}=1}^{4} \mathrm{u}_{\mathrm{pi}}}{4}
$$

Fig. 8. Location of the measuring points and calculation of the total deflection of the panel.

Table 3. Cracking characteristics of tested panels.

\begin{tabular}{|c|c|c|c|}
\hline Specimens & $\begin{array}{c}\text { Cracking load } \\
\qquad P_{c r}[k N]\end{array}$ & $\begin{array}{c}\text { Cracking moment } \\
M_{c r}[\mathrm{kNm}]\end{array}$ & $\begin{array}{l}\text { Deflection at cracking } \\
\qquad a_{c r}[\mathrm{~mm}]\end{array}$ \\
\hline HL-rs-4×4-4.0-1 & 9.32 & 1.19 & 1.19 \\
\hline HL-rs-4×4-4.5-1 & 8.03 & 1.02 & 2.42 \\
\hline HL-rs-4×4-4.5-2 & 8.41 & 1.07 & 3.76 \\
\hline HL-rs-4×4-5.0-1 & 5.96 & 0.76 & 1.99 \\
\hline
\end{tabular}

The cracking stage of the prefabricated panel made using mortar with the smallest amount of water (4.0 litres) occurred at the highest load corresponding with the smallest deformation. This is correlated with the value of flexural strength, which was also the highest compared with other tested samples, differing in water content (Tab. 1).

The panel made using mortar with 5.0 litres of mixing water cracked at the lowest load; the decreasing in cracking load, compared with panel made with 4.0 litres water, amounted to ca. $35 \%$. Such a decreasing of the cracking load resulted from very low flexural strength of the mortar used in this panel.

The panels with 4.5 litres of water (in used mortar) indicated a reduction in cracking load, but it was only about $11 \%$ (average value) compared with panels HL-rs-4x4-4.0-1.

In all the cases, the cracking load was relatively high and equalled about half of the maximum load, what was connected with the type of reinforcement used. The ribbed bars ensured good bonding between reinforcement and the mortar what delayed the cracking stage.

\subsubsection{Load-bearing capacity and failure}

All tested elements failed identically; they were completely, physically destroyed. The behaviour of the panels, during loading process, was also similar. First, at loads equal approximate $50 \%$ of the maximum load recorded, some cracks between the clinker unit and the mortar had appeared. Next, with increasing of the load the width of cracks was also growing up leading to a separation of external units from the entire panel. In the next steps of loading the reinforcement began to deform and destroy the mortar structure. Finally, the element was divided, by cracks, into independent pieces (Fig. 9). This situation was considered a final failure of the panel, when the ultimate load was recorded. In the external parts of panel, the mortar was completely crushed and the reinforcement was separated. Some of the ceramic clinker units were broken (Fig. 10) what resulted in a disintegration of entire panel. This type of failure seems to be dangerous from the safety point of view. 


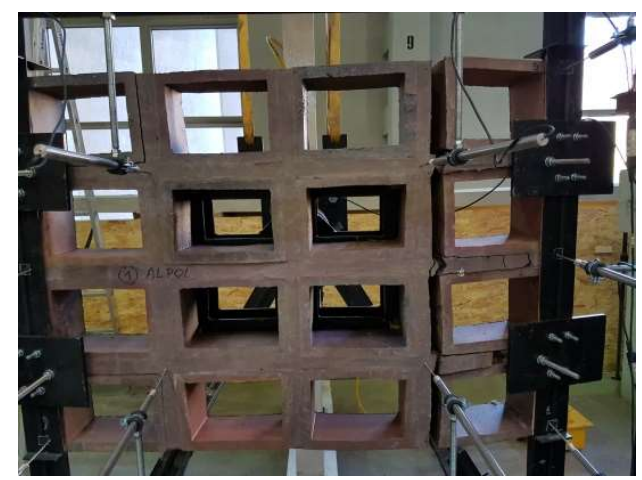

Fig. 9. Disintegration of the panel by vertical cracks.

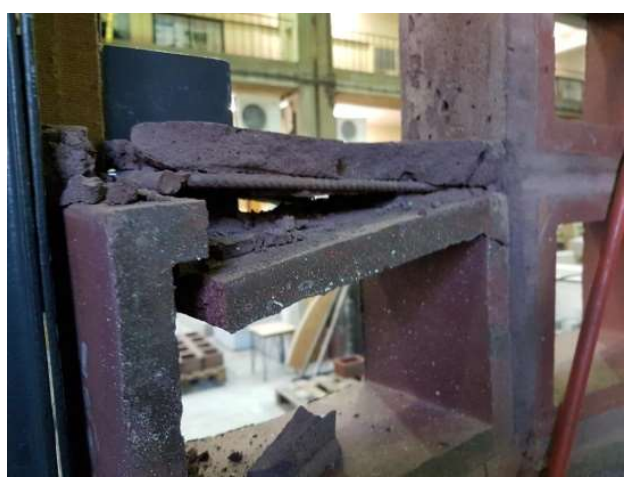

Fig. 10. Damage of a clinker unit; complete crushing of the mortar structure.

Characteristic values of the maximum bending moments $\left(\mathrm{M}_{\max }\right)$ taken as a bending resistance (load-bearing capacity) and the bending moments at failure $\left(\mathrm{M}_{\mathrm{u}}\right)$ are given in Tab. 4. Additionally, the deformations determined at the both stages are listed there.

Table 4. Characteristic values at maximum load reached and at failure.

\begin{tabular}{|c|c|c|c|c|}
\hline Specimens & $\begin{array}{c}\text { Bending } \\
\text { resistance } \\
M_{\max }[\mathrm{kNm}]\end{array}$ & $\begin{array}{c}\text { Deflection at the } \\
\text { maximum load reached } \\
a_{\max }[\mathrm{mm}]\end{array}$ & $\begin{array}{l}\text { Bending moment } \\
\text { at failure } \\
M_{u}[\mathrm{kNm}]\end{array}$ & $\begin{array}{c}\text { Deflection } \\
\text { at failure } \\
a_{u}[\mathrm{~mm}]\end{array}$ \\
\hline HL-rs-4×4-4.0-1 & 2.09 & 18.33 & 1.41 & 37.61 \\
\hline HL-rs-4×4-4.5-1 & 1.95 & 10.07 & 1.48 & 37.58 \\
\hline HL-rs-4×4-4.5-2 & 1.96 & 14.58 & 1.53 & 35.32 \\
\hline HL-rs-4×4-5.0-1 & 1.41 & 14.09 & 0.70 & 38.63 \\
\hline
\end{tabular}

The obtained values of load-bearing capacity of tested panels are associated with the flexural strength of the hardened mortar. The lowest water content (in used mortar) resulted in the highest load-bearing capacity of the panel. The increase of water by only 0.5 litre caused very small reduction, amounted to $6 \%$, in load-bearing capacity. However, further increasing of the water content (by next 0.5 litres) led to a substantial reduction in loadbearing capacity of the panel, comes to more than $30 \%$. The deformations of the panels - at the maximum loads - are various, but in all the cases, they are less than $50 \%$ of the ultimate deformation.

The panels made using mortar with 4.5 and 5.0 litres of water failed by loads reduced no more than $32 \%$ relative to maximum ones. Only, in the panel made using 5.0 litres of water this reduction amounted to ca. 50\%. These decreasing of loads companion the increasing of deformation. $35 \mathrm{~mm}$.

In all the panels, the ultimate deflection was significant and amounted to more than

\subsubsection{Load-deflection relationship}

For the bending moment and the calculated deformation of the panels, the load-deflection relationships were determined. The curves reflected the behaviour of tested elements during loading process are shown in Fig. 11. 


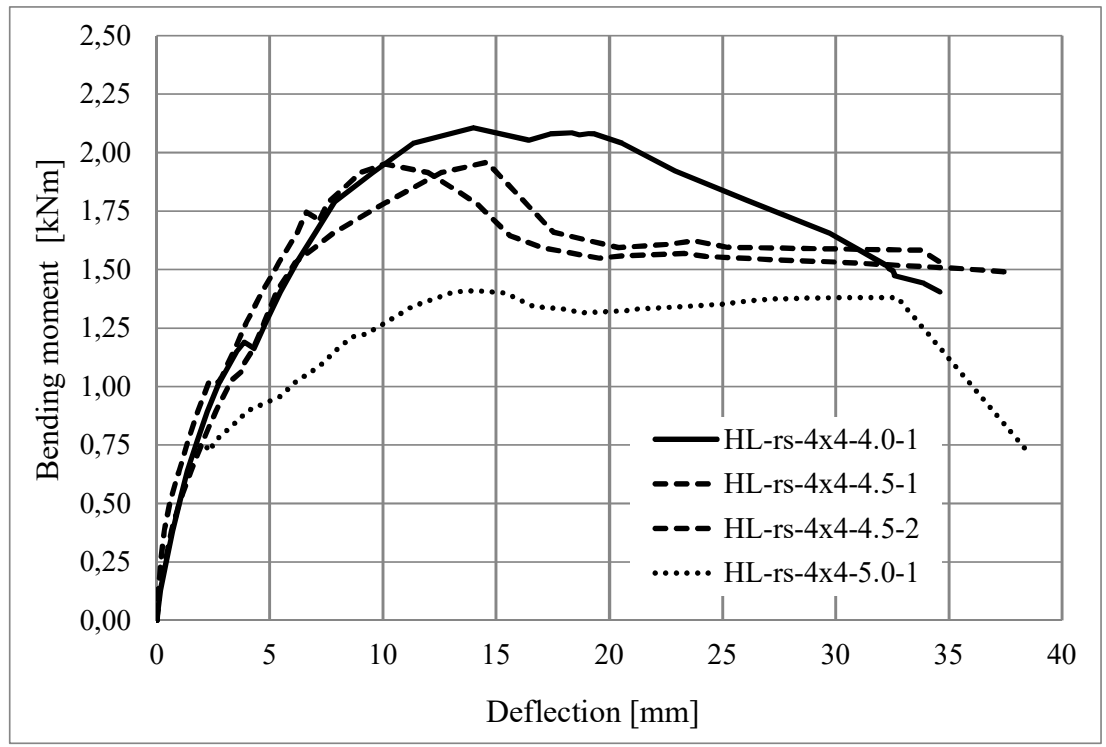

Fig. 11. Relationship between bending moment and total deflection of all panels.

It can be stated, that the amount of mixing water used during prefabrication of the panels has quite significant influence on the behaviour of the panels under out-of-plane bending. In the case of using less mixing water (4.0 and 4.5 litres) the stiffness of these elements is almost similar - up to the reaching the load-bearing capacity. First cracking did not cause a significant change in stiffness, the inclination of the lines is neglected. However, in the panel made with 5.0 litres of water, after first cracking a significant reduction in stiffness was observed.

After reaching the maximum bending moment the loads were decreasing (in all the cases), with simultaneous increasing in the deformations. This process followed relatively slow, what provides some safety level, despite the rapid and dangerous final damage.

\subsubsection{Summary of laboratory test}

The determined flexural and compressive strengths of a hardened mortar) have shown significant differences in values, when using various amounts of mixing water - each times greater than the manufacture's recommendation. An increasing of water content (during preparation of the mortar) caused significant decreasing in flexural strength of the mortar This affected also on the behaviour of the prefabricated panel, made using selected mortar, subjected to out-of-plane bending. The application of 5.0 litres of mixing water leads to the early cracking and decreasing of a load-bearing capacity of the panel, but significantly improves the prefabrication conditions. Analysing this aspect - possibilities of a proper execution of the panel - it is important to consider, that prefabrication of the element using mortar made with 4.0 litres of water is very complicated and require a huge accuracy and precision during filling the empty spaces between reinforcement and unit's surfaces. However, the panel made using 4.0 litres of water provides the best properties; it is characterized by the greatest cracking moment and load-bearing capacity.

Therefore, taking into account the test results obtained (especially cracking loads and bending resistance) and executive processes during prefabrication of the panel using 4.5 litres of mixing water seems to be the acceptable solution. 


\section{Summary and conclusions}

In the case of a factory made dry mix of the mortar the recommended water content needed to preparation of the fresh mix is connected with the proper conduct of bricklaying works at the building site. Using of a recommended by mortar producer water amount guarantee the specific values of the main material properties as well as a proper durability of the mortar. Each untypical use of a mortar, e.g. not for bricklaying works, especially with necessity of using different than recommended water content, should be analysed independently considering the laboratory tests of mechanical and physical (especially porosity, strongly related to the durability) properties. In this paper such a case - but only in terms of the strength parameters - has been described. The influence of an increase of mixing water on the durability of the mortar was analysed separately.

Using of a mortar mix (like a fine concrete) for filling the gaps between masonry units and covering reinforcement forced the use of mortar with a greater workability than usual. Of course, this entailed some changes in its mechanical parameters, which - in this case were determined experimentally.

Considering the presented above materials tests as well as tests of the behaviour of completely prefabricated panels, the following conclusions can be formulated:

- determined strength parameters of a hardened mortar reveal significant differences in flexural and compressive strength values, when using various amount of mixing water - higher than recommended by the producer;

- increasing of a water content caused a significant decreasing in flexural strength of the mortar, as well as in compressive strength values, but significantly improves the execution conditions during prefabrication of a panel;

- using of mortar mixes made with 4.0 litres of water (close to the values recommended by the mortar producer) is very complicated and require a huge accuracy and precision during filling the empty spaces between reinforcement and unit's surfaces;

- the amount of water used in mortar serving to prefabrication of an elevation panel had a significant influence on its stiffness, when loading it out-of-plane, in the entire load range - up to the state of failure; it means that higher water content have a visible influence on a bond strength of the mortar (adhesion between mortar and masonry unit's surface);

- in the case of using small amounts of mixing water (4.0 and 4.5 litres) the stiffness of such prefabricated panels was almost similar - up to the reaching the load-bearing capacity - and the first cracks did not cause significant changes in stiffness. However, in the panel made with 5.0 litres of water, after first cracking a significant reduction in the stiffness as well as bending resistance was observed.

This paper is published thanks to the work NB-307/RB6/2016 and project BK-235/RB6/2017.

\section{References}

1. S. Pavia, R. Hanley, Flexural bond strength of natural hydraulic lime mortar and clay brick, Materials and Structures, 43, 913-922, (2010)

2. A. Costigan, S. Pavia, Influence of mortar water content on the strength of lime mortar masonry, Cork, (2010)

3. J. Hulimka, J. Kubica, M. Kałuża, I. Galman, Prefabricated RM facade panels - search for the safe solution, IOP Conf. Ser.: Mater. Sci. Eng., 245032080 (2017)

4. EN 1015-11:1999 Methods of test for mortar for masonry - Part 11: Determination of flexural and compressive strength of hardened mortar 